\title{
"PARQUES" EM PAISAGEM URBANA E SEU POTENCIAL PARA IMPLANTAÇÃO DE ÁREAS PROTEGIDAS - ESTUDO DE CASO NO SUDESTE DO BRASIL
}

\author{
Maurício Tavares da Mota'; Dra. Eliana Cardoso Leite ${ }^{2}$; Dra. Fernanda Sola ${ }^{3}$
}

RESUMO - O presente trabalho teve como objetivo avaliar os espaços públicos intitulados "Parque" no município de Sorocaba, a método de avaliação se constitui em três etapas: identificação das áreas, pesquisa bibliográfica sobre o conceito; elaboração de uma proposta de seleção das áreas com maior relevância ambiental, com base nos critérios: tamanho, percentual de cobertura florestal nativa e função destes espaços; avaliação sistemática destes espaços, assim como construção de um índice de qualidade ambiental para áreas selecionadas. Foram identificados 33 parques, pelo método proposto $42,5 \%$ foram excluídos pelo critério tamanho, 42,5\% pelo critério percentual de vegetação mínima, 5 preencheram requisitos favoráveis para instituição de unidades de conservação. Da área territorial de todos os parques, $41 \%$ apresentam cobertura florestal nativa, $42 \%$ destes apresentam área menor que 5 ha, juntos são responsáveis por apenas $5 \%$ da cobertura florestal, os cinco parques selecionados com potencial para instituição de unidades de conservação são responsáveis por $47 \%$ da cobertura florestal. Concluímos que não há normas ou critérios para instituição dos espaços públicos intitulados como "Parque" no município, este fato traz prejuízos na gestão eficaz destes espaços. Foi identificada ainda a necessidade de alterações no SNUC para abranger estes espaços em meio urbano.

Palavras-chave: Parques Naturais Municipais; Parques urbanos; Espaços livres; Unidades de conservação.

\section{PARKS IN THE URBAN LANDSCAPE AND ITS POTENTIAL FOR DEPLOYMENT OF PROTECTED AREAS - CASE STUDY IN SOUTHEASTERN BRAZIL.}

ABSTRACT -The present study aimed to evaluate the public spaces entitled "Park" in the city of Sorocaba, the evaluation methodology is in three steps: identification of areas, bibliographical research on the concept; preparation of a proposal for selection of areas with greater environmental relevance, based on the criteria: size, percentage of native forest cover and function of these spaces; systematic evaluation of these spaces, as well as construction of an environmental quality index for selected areas. 33 parks, were identified by the methodology proposed $42.5 \%$ were excluded by size, by $42.5 \%$ percent of minimum vegetation, five met favourable requirements for establishing protected areas. The land area of all parks, $41 \%$ have native forest cover, $42 \%$ of these feature area less than 5 ha, together account for only 5 of the forest cover, the five selected parks as potential for establishment of conservation units are responsible for $47 \%$ of the forest cover. We conclude that there are no standards or criteria for the institution of public spaces titled as "Park" in the city, this fact brings losses in effective management of these spaces, was identified the need for changes in the SNUC to cover these urban spaces

Key-words: Municipal parks; Urban parks; Open spaces; Conservation units.

\footnotetext{
${ }^{1}$ Biólogo - Mestrando do PPGSGA - Programa de Pós Graduação em Sustentabilidade na Gestão Ambiental, Universidade Federal de São Carlos -UFSCAR- campus Sorocaba-SP. E-mail:< mauriciotavaresmota@gmail.com $>$

${ }^{2}$ Docente - Universidade Federal de São Carlos -UFSCAR- campus Sorocaba. NEAPS- Núcleo de Estudos em Áreas Protegidas e

Sustentabilidade, PPGSGA- Programa de Pós Graduação em Sustentabilidade na Gestão Ambiental, PPGDBC- Programa de Pós Graduação em Diversidade Biológica e Conservação. Rod. João Leme dos Santos, km 110- Sorocaba/SP. E-mail:< eliana.leite@ufscar.br $>$

${ }^{3}$ Doutora em Ciência Ambiental pelo Instituto de Eletrotécnica e Energia- PROCAM/USP. Pesquisadora da Universidade de São Paulo.

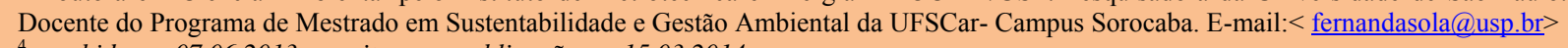
${ }^{4}$ recebido em 07.06.2013 e aceito para publicação em 15.03.2014
} 


\section{INTRODUÇÃO}

A gênese da proteção de espaços livres ocorreu por motivação religiosa em sociedades primitivas. No ocidente, segundo relato histórico, os primeiros espaços protegidos surgiram para garantir território de caça ou garantir recursos da flora à realeza e a aristocracia (VALLEJO, 2009).

Os espaços protegidos intitulados "Parques", de acordo com Scalise (2002), se originaram a partir da reforma da arquitetura urbana proposta por Georges-Eugène Haussmann, em Paris entre 1850-1860, e influenciou toda a Europa. Na América ocorreu o Movimento dos Parques Americanos, liderado por Frederick Law Olmstesd em Nova Iorque, Chicago e Boston, este movimento promoveu a construção de grandes jardins de contemplação e parques de paisagem. O objetivo era atender demandas por espaços para recreação, lazer, contemplação e amenização dos danos ocasionados pela intensa industrialização promovida pela revolução industrial.

A concepção de espaços protegidos maiores com foco na conservação de áreas naturais (“wilderness"), proteção de belezas cênicas, biodiversidade e manutenção de serviços ambientais surgiu no final século ainda no XIX nos Estados Unidos e teve como marco a instituição do Parque Nacional de Yellowstone, sua perspectiva era conservacionista e dicotômica entre "homem" e "natureza" e, logo foi disseminada para vários países (VALLEJO, 2009).

Desde então, a concepção de espaços protegidos evoluiu e a utilização da terminologia "Parque" foi apropriada tanto por urbanistas como por conservacionistas e, incorporada a outras áreas, este fato de acordo com Benaduce (2007), provocou multiplicidade de expressões e imprecisão conceitual.

Nos espaços urbanos, mecanismos legais preveem manutenção de espaços verdes reservados em loteamentos e intervenções urbanísticas como mecanismo compensatório pelo impacto ambiental. Estes são transferidos compulsoriamente ao domínio público e o percentual da área loteada é variável de acordo com a legislação municipal. Esses espaços se tornam patrimônio de toda a comunidade, bens de uso comum do povo, dotados de proteção jurídica, de caráter inalienável e impenhorável, com uma clara missão social e ambiental. Nesse sentido, o artigo 17, da Lei Federal n. 6.766/79, veda a mudança na destinação dessas áreas para qualquer outro fim que não atenda o caráter socioambiental pelo qual foram instituídas. Benaduce (2007), identificou que em São Paulo $40 \%$ das áreas dos parques tiveram esta origem. Em outros casos, os espaços provêm de desapropriações para fins de proteção a bem do interesse público, quando seus atributos assim justificarem (RANGEL E RIBEIRO, 2010). A gestão destas áreas por parte dos municípios brasileiros é confusa, em sua maioria não há meios de tipificação e se misturam conceitualmente espaços com vocação para fins urbanísticos daqueles com potencialidade para conservação.

Sorocaba não foge à regra, dentre seus inúmeros espaços livres públicos, muitos dos quais comumente denominados "Parques" podem ter equivalência às unidades de conservação como previsto no Sistema Nacional de Unidades de Conservação - SNUC (BRASIL, 2000), por suas características de biodiversidade e conservação de 
recursos do meio físico, porém outros apresentam pequena dimensão, pequeno ou ausente percentual de cobertura florestal nativa e função principal urbanística. É concluso que há uma evidente generalização do conceito "Parque", também observada em outros municípios por Lima et al. (1994); Richter (1981); Tandy (1982) (apud LIMA et al. 1994); Loboda e Angelis (2005); Bruccheri e Nucci (2006), Oliveira (2007), Coporusso e Matias (2008) e Pereira (2011). O termo "Parque" é utilizado indiscriminadamente no sentido de Parque Urbano e no sentido de Parque Natural Municipal. Neste contexto, o objetivo deste trabalho foi analisar as características físicas, bióticas e uso dos espaços livres públicos intitulados "Parque" no município de Sorocaba, descrever se a instituição destes espaços está relacionada a normas, regras ou critérios para sua instituição, propor método baseado em características física e bióticas que faça distinção entre os espaços com características predominantemente urbanísticas daqueles com vocação para conservação, assim como construir e aplicar nestas áreas selecionadas um índice de “qualidade ambiental" com objetivo de avaliar se as mesmas tem potencial para implantação de áreas protegidas.

\section{MATERIAIS E MÉTODOS}

\section{Caracterização da área}

A área de estudo foi o município de Sorocaba, situado a Sudoeste do Estado de São Paulo, entre as coordenadas $22^{\circ} 45^{\prime}$ e $24^{\circ}$ Sul e $47^{\circ}$ e $48^{\circ} 15^{\prime}$ Oeste. Segundo dados oficiais do IBGE (2012) têm população de aproximadamente 586.625 habitantes e extensão territorial de $448,989 \mathrm{~km}^{2}$. O atual Plano Diretor (Lei Municipal n. 8.181/2007) caracteriza esta extensão em 17,6\% como rural, 71,17\% urbana e $11,23 \%$ industrial.

\section{Metodologia}

O método de investigação foi dividido em três etapas, a etapa 01 consistiu em uma análise documental e cartográfica dos parques instituídos em Sorocaba; etapa 2 - avaliação preliminar de todos estes espaços com proposição de critérios de distinção entre os espaços com vocação urbanística,
A vegetação remanescente se compõe dos biomas Mata Atlântica e Cerrado, com predomínio da Floresta Estacional Semidecidual (KRONKA, 2005). De acordo com Mello (2012), há um alto grau de fragmentação da vegetação natural no município sendo que d total de 2.537 fragmentos florestais correspondem a $16,68 \%$ do território. Dos fragmentos identificados pela autora, $62 \%$ são menores que 1 ha.

daqueles com potencial para instituir unidades de conservação; etapa 3 - análise detalhada dos espaços selecionados com potencial para conservação, utilizando para isto um índice de qualidade ambiental construído com objetivo de avaliar seus atributos naturais. 


\section{Etapa 1}

Esta fase consistiu na realização de levantamento bibliográfico, fonte secundária, com objetivo de analisar o tratamento doutrinário de Áreas Verdes Urbanas, Parques e Unidades de Conservação. Foram objeto de análise os sistemas municipais brasileiros e estrangeiros que de alguma forma apresentaram tipologia e classificação sugerida pela doutrina dominante. Foi consultado também textos de leis, decretos e instrumentos jurídicos análogos, fonte primária.

Para a área de estudo, foram identificados os instrumentos legais de criação dos parques (Leis e Decretos), dados que permitiram avaliar a

\section{Etapa 2}

Foram realizadas visitas em outubro e novembro de 2012 a todos os parques e seu entorno, com objetivo de identificar as características físicas, bióticas, ocupação do solo e usos destes espaços pela população. As características de tamanho, ocupação por vegetação nativa em fragmento, forma de ocupação do entorno, presença de infraestrutura urbana, rural, natural, industrial ou residencial foram analisadas e tiveram como referência os trabalhos de Angelis et al (2004); Benini \& Martin (2010), Bellester-Olmos \& Carrasco (2001).

Nesta etapa o objetivo foi distinguir os espaços com características e vocação para cumprir funções urbanísticas (parques urbanos, praças, áreas verdes, bosques, jardins, largos, hortos, outros), daqueles cujas características naturais justificam a criação ou manutenção de Áreas Protegidas, utilizando-se como referência as características de Unidades de Conservação (UC) previstas no SNUC (BRASIL, 2000). localização, levantamento cartográfico, dimensão e função destes espaços.

Para o levantamento cartográfico, foram utilizadas 66 fotografias aéreas digitalizadas em escala 1: 20.000, com resolução espacial de 0,4 metros, do ano de 2006, que compõem todo o Território do município, fornecidas pela Prefeitura Municipal. Estas imagens foram vetorizadas, georreferenciadas e exportadas para o software $\operatorname{ArcGis}{ }^{\circledR}$ 9.0, com objetivo de identificar, localizar e delimitar sua extensão territorial, área terrestre, recursos hídricos, cobertura vegetal e extensão da área de preservação permanente.

A utilização do critério tamanho utilizado é defendida por Burke et al (2009), Barragán (2001); Morsello (2001), que citam conceitos da teoria da biogeografia de ilhas (MAC ARTHUR E WILSON, 1967) para defender tamanhos mínimos, variáveis em decorrência das espécies a serem protegidas. Desta forma, foi proposto a divisão em classes de tamanho descrita na Tabela 1, onde foram excluídos aqueles espaços menores que 5 ha. A justificativa para este critério de exclusão tem fundamento nos problemas relacionados ao efeito de borda (BORGES et al, 2004). A utilização do dado percentual mínimo de cobertura florestal nativa, como critério de exclusão, fundamenta-se na necessidade de uma área mínima de vegetação para cumprir funções ambientais, conceito este defendido por Avelar \& Silva Neto (2008); Falcón (2008); Guzzo (2006); Bellester-Olmos \& Carrasco (2001) e Cavalheiro et al (1992), desta forma, foram excluídas as áreas que não apresentaram percentuais mínimos variáveis em relação ao 
tamanho da área, como descrito na Tabela 1, não sendo consideradas árvores isoladas, apenas fragmentos nativos. O percentual mínimo de vegetação é reduzido de forma gradativa em decorrência do tamanho da área com objetivo de garantir uma área mínima de vegetação que pode variar de 3,5 ha a 40 ha ou mais em decorrência do tamanho da área. Os parâmetros estabelecidos como mínimos de tamanho e ocupação por vegetação se justificam ainda pelas conclusões de Liira et al (2012) que constataram que as melhores condições de fragmento de floresta nos bosques de solares antigos em áreas rurais, são definidas em termos de uma superfície mínima de 2,5 ha.

Tabela 01. Percentuais mínimos de tamanho e cobertura florestal das áreas analisadas.

\begin{tabular}{c|c}
\hline Classes de tamanho & Percentual mínimo de fragmento florestal (área terrestre) \\
\hline$<5$ ha & Exclui \\
\hline 5,1 à 10 ha & $70 \%$ \\
\hline 10,1 à 50 ha & $60 \%$ \\
\hline 50,1 à 100 ha & $50 \%$ \\
\hline Mais de 100,1 ha & $40 \%$ \\
\hline
\end{tabular}

A função foi outro conceito considerado, neste quesito foi priorizada a conservação de atributos naturais e identificada ocorrência de estrutura de acesso que possibilite a recepção de visitantes, em decorrência da presença de equipamentos de uso público.

O entorno foi avaliado através do diagnóstico do uso do solo nas imediações do "parque". Foram consideradas preferenciais aquelas áreas cujo entorno seja dotado de atributos naturais que permitam a conectividade a outros fragmentos florestais, como terrenos desprovidos de construção, existência de reflorestamentos nativos,

\section{Etapa 3}

Apenas as áreas selecionadas e identificadas como potenciais para conservação e criação de áreas protegidas na etapa 2 , foram objeto de análise nesta fase.

Estas foram avaliadas de forma sistemática através de um índice de "qualidade ambiental" construído para estes espaços. A seleção dos indicadores que compõem este índice foi baseada nos trabalhos de: Angelis et al (2004); Bellester-Olmos \& Carrasco exóticos, avenidas largas e arborizadas, dentre outros.

Foram consideradas delimitações territoriais sem características para criação de áreas protegidas, aquelas com dimensões inferiores a 5 ha; áreas com percentuais de vegetação nativa em fragmento contínuo inferiores aos percentuais descritos na Tabela 1; espaços cuja função principal seja o lazer, recreação, práticas esportivas e convívio social com uso direto e o entorno com intensa urbanização e ocupação (urbanização densa e consolidada, rodovias, indústrias).

(2001); Benini \& Martin (2010); Cavalheiro \& Del Picchia (1992); Durigan et al, 2006; Kliass (1993); Pereira (2011); Sanchotene (2004); Souza (2010), e estão descritos na Tabela 2.

O conceito de índice considerado neste trabalho teve como referência Siche et al (2007), que define índice como um valor numérico que representa a interpretação da realidade de um sistema, utilizando em seu cálculo um método. 
Dentre os indicadores, o tamanho da área levou em consideração os resultados obtidos por Mello (2012) que identificou a variação de tamanho dos fragmentos de vegetação nativa remanescentes em Sorocaba.

Para cada um dos indicadores foi atribuído uma nota entre 0 e 10, variável de acordo com o número de características analisadas e sua importância, considerando que cada característica descrita tem como referencial uma situação desejável para preservação de espaços naturais de forma integral. Método semelhante foi utilizada por Durigan et al (2006) em estudo para criação de áreas protegidas no Bioma Cerrado, para o Estado de São Paulo.

O índice construído para os parques de Sorocaba tem como cálculo a somatória de notas de cada indicador multiplicado por fator de correção de 1,11, para permitir que somatória das notas máximas atinja 100. Os espaços com maiores notas refletem a ocorrência de atributos que lhe conferem melhores características naturais em relação as demais áreas analisadas.

Os indicadores 1, 3, 5 e 6 (Tabela 2) foram analisados por meio de imagens aéreas obtidas na Prefeitura Municipal de Sorocaba, vetorizadas e trabalhadas com auxílio do software ArcGis ${ }^{\circledR}$ 9.0. Após esta análise prévia, estes indicadores foram checados em campo para testar a veracidade das informações.

Os indicadores 2, 4, 5 e 7 foram analisados em campo, para identificação do estágio sucessional da vegetação com características florestais (indicador 2) sendo utilizada como referência a Resolução CONAMA n. 10/93 e 01/94. O método de análise consistiu em selecionar de forma aleatória em cada parque unidades amostral (transectos) com dimensões de $05 \times 20 \mathrm{~m}$ em número de 03 repetições por área, totalizando uma área amostral de $300 \mathrm{~m}^{2}$, Estes foram locados em campo distantes no mínimo 10 metros, uma da outra.

Nestas unidades amostrais foram tomadas as medidas de todos indivíduos com CAP (circunferência a altura do peito) $\geq 10 \mathrm{~cm}$, além da altura de todos indivíduos arbóreos do dossel (indivíduos lenhosos mais altos no ponto) e realizadas os demais registros necessários para identificar o estágio sucessional da vegetação de cada parque.

As epífitas foram analisadas segundo sua presença ou ausência, através de estimativa visual, classificadas como raras quando cobriam até $5 \%$ da superfície arbórea da parcela em análise $5 \%$, pouco, quando o percentual de cobertura variou entre 05 e $25 \%$ e muito, quando o percentual de cobertura foi superior a $25 \%$ da cobertura.

As trepadeiras foram analisadas segundo indicação apontada na Res. CONAMA n. 01/94 e seu potencial como espécie indicadora (GENTRY, 1991). Para sua indicação de presença e ausência na área da parcela, foi utilizada como critério a observação visual ao longo da área amostral. A classificação das lianas de caule lenhosas e lianas herbáceas (vegetais sem tecido lenhoso que se desenvolvem apoiando-se em um suporte, geralmente outras plantas) tem como base a classificação proposta por Whittaker (1978).

A presença de herbáceas heliófitas (gramíneas) foi diagnosticada pela observação visual, sua ocorrência na área da parcela foi classificada como: rara ou ausente, quando o percentual de ocupação na parcela variar entre 0 a $5 \%$; pouca, quando este percentual variar entre 5 a $25 \%$; muito, quando sua ocupação for superior a 25\%). As espécies indicadoras apontadas na Res. CONAMA n. 01/94 foram utilizadas para melhor caracterização das áreas. 
O indicador uso do solo (indicador 3 da Tabela 2) no entorno, busca diagnosticar a ocupação do solo nas imediações do parque, este tem como cenário desejável a conexão com outros fragmentos florestais. Sua análise ocorreu de forma diferenciada de acordo com os usos mais comuns no município. Foi considerado o uso que ocorre em predomínio ( $50 \%$ ou mais das áreas) do entorno, a análise deste item tem como referência conceitos de manutenção das áreas de amortecimento em unidade de conservação, atribuída como fundamental para manutenção dos atributos naturais, enfatizado por Ishihata (1999); Morsello (2001).

$\mathrm{O}$ indicador 5 (Tabela 2), foi primeiramente analisado nas imagens aéreas e as informações foram checadas no campo por meio de análise visual.

O indicador 7 (Tabela 2), consistiu analisar a presença de infraestrutura para uso de lazer e recreação, como equipamentos para prática de esportes, convívio social e lazer.

Tabela 02. Índice utilizado para avaliação das áreas selecionadas como potenciais para categorização no SNUC no Município de Sorocaba.

Table 02: Index used for assessment of selected areas as potential for categorization in the SNUC in the municipality of Sorocaba.

\begin{tabular}{|c|c|c|c|}
\hline INDICADOR & \multicolumn{2}{|c|}{ CLASSE } & $\begin{array}{c}\text { NOT } \\
\text { A }\end{array}$ \\
\hline \multirow{16}{*}{$\begin{array}{l}\text { 1. Vegetação } \\
\text { Nativa } \\
\text { Arbórea em } \\
\text { fragmento }\end{array}$} & \multicolumn{2}{|c|}{ 1.a.Composição- Exótica e Nativa } & 05 \\
\hline & \multicolumn{2}{|c|}{ - Nativa } & 10 \\
\hline & \multirow{6}{*}{ 1.b.Percentual total de Vegetação } & $40-50 \%$ & 1 \\
\hline & & $51-60 \%$ & 2,8 \\
\hline & & $61-70 \%$ & 4,6 \\
\hline & & $71-80 \%$ & 6,4 \\
\hline & & $81-90 \%$ & 8,2 \\
\hline & & $91-100 \%$ & 10 \\
\hline & \multirow{8}{*}{ 1.c.Vegetação nativa fora de APP } & $<20 \%$ & 1 \\
\hline & & $20,1-30 \%$ & 2,29 \\
\hline & & $30,1-40 \%$ & 3,58 \\
\hline & & $40,1-50 \%$ & 4,87 \\
\hline & & $50,1-60 \%$ & 6,16 \\
\hline & & $60,1-70 \%$ & 7,45 \\
\hline & & $70,1-80 \%$ & 8,74 \\
\hline & & $>80,1 \%$ & 10 \\
\hline \multirow{3}{*}{$\begin{array}{l}\text { 2. Estágio } \\
\text { sucessional } \\
\text { da vegetação }\end{array}$} & \multicolumn{2}{|c|}{ Estágio de regeneração inicial } & 3,33 \\
\hline & \multicolumn{2}{|c|}{ Estágio de regeneração médio } & 6,66 \\
\hline & \multicolumn{2}{|c|}{ Estágio de regeneração avançado } & 10 \\
\hline \multirow{4}{*}{$\begin{array}{l}\text { 3. Área } \\
\text { territorial }\end{array}$} & \multicolumn{2}{|c|}{5,1 à 10 ha } & 02 \\
\hline & \multicolumn{2}{|c|}{10,1 à 50 ha } & 04 \\
\hline & \multicolumn{2}{|c|}{50,1 à 100 ha } & 08 \\
\hline & \multicolumn{2}{|c|}{ Mais de 100,1 ha } & 10 \\
\hline \multirow{3}{*}{$\begin{array}{l}\text { 4. Uso do solo } \\
\text { no entorno }\end{array}$} & \multicolumn{2}{|c|}{ Urbanizada, vias pavimentadas. } & 01 \\
\hline & \multicolumn{2}{|c|}{ Pastagens } & 2,8 \\
\hline & \multicolumn{2}{|c|}{ Indústrias } & 4,6 \\
\hline \multirow{3}{*}{$\begin{array}{c}\text { Nota }=\text { média } \\
\text { das notas de } \\
\text { ocorrência. }\end{array}$} & \multicolumn{2}{|c|}{ Agricultura anual } & 6,4 \\
\hline & \multicolumn{2}{|c|}{ Silvicultura } & 8,2 \\
\hline & \multicolumn{2}{|c|}{ Vegetação Nativa } & 10 \\
\hline
\end{tabular}




\begin{tabular}{|c|c|c|}
\hline \multirow{3}{*}{$\begin{array}{c}\text { 5roteção de } \\
\text { manancial }\end{array}$} & Sem curso d'água & 01 \\
\cline { 2 - 3 } & Com curso d água, sem nascentes & 04 \\
\cline { 2 - 3 } & Nascentes & 07 \\
\hline \multirow{3}{*}{$\begin{array}{c}\text { 6. Conectividad } \\
\text { e }\end{array}$} & Várzeas ou brejos + nascentes & 10 \\
\cline { 2 - 3 } & Sem fragmentos em raio de $100 \mathrm{~m}$ & 01 \\
\cline { 2 - 3 } & Com fragmentos em raio $>100 \mathrm{~m}$ & 3,3 \\
\cline { 2 - 3 } & Fragmentos $<100 \mathrm{~m}$ não conectados e área $\leq 50$ ha. & 7,8 \\
\cline { 2 - 3 } & Fragmentos $<100 \mathrm{~m}$ conectados e área $\leq 50$ ha. & 10 \\
\hline \multirow{2}{*}{ 7. Função } & Fragmentos $<100 \mathrm{~m}$ conectados e área $>100$ ha. & 6,66 \\
\cline { 2 - 3 } & Lazer, recreação, esporte e convívio social. & 10 \\
\cline { 2 - 3 } & Histórica, arquitetônica & $\mathbf{1 0 0}$ \\
\hline
\end{tabular}

\section{RESULTADOS E DISCUSSÃO}

A análise jurídica sobre a existência de normas que definam os espaços livres públicos restou infrutífera, visto que não há uniformidade na legislação, e muitas vezes se verifica que a legislação apenas tangencia o conceito de forma aberta e pouco específica, permitindo que os municípios instituam "Parques" ao seu próprio alvedrio. Dessa forma, a consulta à legislação não atendeu o propósito de se conceituar o termo. Alguns autores apresentam certos aspectos em comum, entretanto, as distintas abordagens corroboram com as conclusões de Lima et al. (1994); Richter (1981); Loboda e Angelis (2005); Coporusso e Matias (2008) e Pereira (2011), de que não há um método universal de classificação das tipologias dos espaços verdes públicos, sendo variável em razão das necessidades locais e de aspectos culturais diversificados. Em todas as propostas analisadas a classificação tem como base a função do espaço na cidade, o tamanho e em alguns casos é levado em consideração o percentual de cobertura florestal, porém, com parâmetros muito variáveis.

A adoção da terminologia "parque" para os espaços verdes públicos surge no século XX, com objetivo de promoção à sociabilidade e ao contato físico com a natureza (COSTA, 2011). Desde então, diversos autores abordam de forma distinta os aspectos que definem o termo. A pesquisa das leis e decretos municipais de Sorocaba que instituem os "parques" mostra a existência de 33 parques (Tabela 3), dos quais 25 foram instituídos após a criação do SNUC, destes apenas o Parque Natural Municipal "Corredores da Biodiversidade" foi instituído como unidade de conservação.

Estes totalizam uma extensão territorial de 1.593,87 ha o menor tem 0,28 ha e maior tem 1.074 ha. Apenas como referência foram encontradas algumas publicações em poucas localidades que utilizaram aferições de espaços livres semelhantes. Galvão et al (2003), identificaram em Curitiba - PR (ano 2000), 14 parques, estes perfazem uma extensão de 1.841 ha, além de 13 bosques com uma extensão territorial de 63,3 ha, o menor parque de Curitiba - PR tem 4,6 ha. Gomes (2009), identificou em Ribeirão Preto 17 parques que totalizam uma extensão territorial de 194,3 ha, sendo que o menor parque tem 1,1 ha e o maior 27,5 ha.

No presente estudo, foram observadas divergências nas áreas de alguns parques, entre a prevista em seu instrumento legal de instituição (Lei ou Decreto - 
Tabela 3) e aquela observada em campo e por cartografia. Esta divergência ocorreu pela incorporação de outras áreas públicas vizinhas ao parque, entretanto, não interferiram na aplicação do método proposto.

Tabela 03. Parques instituídos em Sorocaba e seu respectivo instrumento de criação. *Áreas eliminadas pelo critério tamanho, **áreas eliminadas pelo critério percentual de vegetação, áreas selecionadas como potenciais para instituir Unidades de Conservação em negrito.

Table 03 . Established parks in Sorocaba and its instrument of creation. *Deleted areas by size, **eliminated by percentage criterion of vegetation, selected areas as potential to establish protected areas in bold.

\begin{tabular}{|c|c|c|c|c|c|}
\hline \multirow[b]{2}{*}{ Id } & \multirow[b]{2}{*}{ Parque } & \multirow{2}{*}{$\begin{array}{c}\text { Área } \\
\text { (ha) }\end{array}$} & \multirow{2}{*}{$\begin{array}{c}\text { Cobertura } \\
\text { vegetal } \\
(\%)\end{array}$} & \multicolumn{2}{|c|}{ Vegetação (\%) } \\
\hline & & & & $\begin{array}{c}\mathbf{E m} \\
\mathbf{A P P}\end{array}$ & $\begin{array}{l}\text { Fora de } \\
\text { APP }\end{array}$ \\
\hline 1 & $\begin{array}{l}\text { Pq. Natural Dr. Braulio Guedes da Silva (Lei n. 4.934/95; Lei n. } \\
\text { 4043/92) }\end{array}$ & 9,38 & 71,55 & 61,45 & 38,55 \\
\hline 2 & $\begin{array}{l}\text { Pq. Linear - Armando Pannunzio (Lei. N. 8.521/08 - Decreto n. } \\
19.518 / 11 \text { )** }\end{array}$ & 1074 & 0,5 & 100 & 0 \\
\hline 3 & Pq. Maestro Nilson Lombardi (Lei n. 8.449/08)** & 7,31 & 0,00 & 0 & 100 \\
\hline 4 & Pq. Flávio Trettel - Vila Formosa (Lei n. 8.446/08)** & 11,95 & 9,17 & 48,85 & 51,15 \\
\hline 5 & Pq. Natural Antônio Latorre (Lei n. 7.985/06)* & 4,45 & 19,10 & 6,57 & 93,43 \\
\hline 6 & Pq. Natural Juracy Antônio Boaro (Lei n. 7.940/06)* & 1,87 & 71,00 & 73,2 & 26,8 \\
\hline 7 & $\begin{array}{l}\text { Pq. Maria Barbosa Silva - (Lei n. 7.855/06 - Decreto n. } \\
17.887 / 09)^{* *}\end{array}$ & 16,39 & 2,98 & 75,12 & 24,88 \\
\hline 8 & Pq. Kasato Maru (Lei n. 7.845/06)* & 0,94 & 17,29 & 100 & 0 \\
\hline 9 & Pq. Santi Pegoretti Maria Eugênia (Lei n. 7.807/06)** & 20,56 & 29,69 & 75,12 & 24,88 \\
\hline 10 & Pq. Natural João Pellegrini (Lei n. 7.665/06)* & 2,59 & 10,31 & 43,04 & 56,96 \\
\hline 11 & Pq. Yves Ota (Lei n. 7.405/06)** & 12,03 & 45,87 & 63,84 & 36,16 \\
\hline 12 & $\begin{array}{l}\text { Pq. Natural da Cachoeira - Dr. Eduardo Alvarenga (Lei n. } \\
7.379 / 05)^{* *}\end{array}$ & 15,82 & 17,95 & 79,48 & 20,52 \\
\hline 13 & Pq. Raul de Moura Bittencourt (Lei n. 7.301/04)** & 20,58 & 31,06 & 49,5 & 50,5 \\
\hline 14 & Pq. Natural Chico Mendes (Lei n. 3.034/89) & 15,17 & 77,73 & 30,26 & 69,74 \\
\hline 15 & Pq. Quinzinho de Barros - Zoológico (Lei n. 1.087/63)** & 13,15 & 32,7 & 18,05 & 81,95 \\
\hline 16 & Pq. Municipal Mario Covas (Lei n. 6.416/01) & 52,67 & 83,14 & 36,43 & 63,57 \\
\hline 17 & Pq. Dos Espanhóis (Lei n. 8.536/08)* & 4,74 & 9,17 & 66,71 & 33,29 \\
\hline 18 & Pq. João Câncio Pereira - Pq. Água Vermelha (Lei n. 3.403/90)* & 2,02 & 50,54 & 93,21 & 6,79 \\
\hline 19 & Pq. Pedro Paes de Almeida - Horto Municipal (Lei n. 2.815/88) & 21,75 & 72,04 & 31,88 & 68,12 \\
\hline 20 & $\begin{array}{l}\text { Pq. Natural Municipal Corredores da biodiversidade (Lei n. } \\
\text { 10.071/12) }\end{array}$ & 62,47 & 49,62 & $\mathbf{3 4 , 8}$ & 64,2 \\
\hline 21 & $\begin{array}{l}\text { Pq. Carlos Alberto de Souza (Decreto n. 14.418/05; Lei n. } \\
5.963 / 99)^{* *}\end{array}$ & 10,43 & 20,71 & 61,16 & 38,84 \\
\hline 22 & Pq. Brigadeiro Tobias (Decreto n. 19.372/11; Lei n. 9.889/11)* & 4,56 & 28,28 & 94,79 & 5,21 \\
\hline 23 & Pq. Jd. Botânico (Decreto n. 18.567/10; Lei n. 9.918/12)** & 6,51 & 18,43 & 0 & 19,80 \\
\hline 24 & Pq. Do Éden (Decreto n. 18.468/10)* & 0,81 & 7,40 & 85,73 & 14,27 \\
\hline 25 & Pq. Walter Grillo (Lei n. 8.506/08 - Decreto n. 18.287/10)* & 1,56 & 40,38 & 43,72 & 56,28 \\
\hline 26 & Parque da Cidade (Decreto n. 17.883/09 - 17.902/09)** & 120 & 28,14 & 48,91 & 51,09 \\
\hline 27 & Pq. Pirajibu (Decreto n. 16.432/09)** & 46,8 & 48,44 & 53,53 & 46,47 \\
\hline 28 & Pq. Da Biquinha (Lei n. 9.956/12)* & 2,88 & 86,80 & 67,02 & 32,98 \\
\hline 29 & Pq. Ouro Fino (Lei n. 9.963/12)** & 9,69 & 47,6 & 79,25 & 20,75 \\
\hline 30 & Pq. Antônio Amaro Mendes - Jd. Brasilândia (Lei n. 8.440/08)* & 3,35 & 22,08 & 75,16 & 24,84 \\
\hline 31 & Pq. Municipal Profa. Margarida L. Camargo (Lei n. 7.155/04)* & 1,91 & 11 & 58,56 & 41,44 \\
\hline 32 & Pq. Miguel Gregório de Oliveira (Lei n. 6.443/01)* & 15,25 & 26,69 & 82,66 & 17,34 \\
\hline 33 & Pq. Steven Paul Jobs (Lei n. 10.070/12)* & 0,28 & 96,42 & 94,79 & 5,21 \\
\hline
\end{tabular}


Os Parques de Sorocaba apresentam uma evidente heterogeneidade de tamanhos, dos 33 parques identificados $14(42 \%)$ são menores que 5 ha, 5 (12\%) variam entre 5,1 e 10 ha; 11 (33\%) variam entre 10,1 e 50 ha; $2(6 \%)$ variam entre 50,1 e 100 ha e $1(3 \%)$ tem tamanho superior à 100 ha. Este cenário enfatiza a fragmentação identificada por Mello (2012), também presente em cidades médias e grandes no Brasil e América latina. $\mathrm{Na}$ região metropolitana de Santiago, Chile, Paecke et al (2011) constataram que apenas 3\% das áreas verdes são maiores que 1 ha.

Porém há localidades que o cenário difere, Galvão et al (2003), citam que apenas os 3 maiores parques são responsáveis por $88 \%$ da área total de parques de Curitiba - PR, o restantes apresentam média de tamanho de 20,4 ha, embora os autores atentam para a pequena extensão territorial dos parques de Curitiba em se tratando de conservação da natureza, estes apresentam área territorial muito superior aquelas identificadas em Sorocaba. Em Santo André, Lavendowski et al. (2007), identificaram 10 parques com área total de 53,2 ha. Em Osasco, Shibuya e Kakizaki (2011), identificaram 6 que perfazem uma extensão de 23,98 ha.

Com relação a vegetação presente nestes espaços, em Recife-PE Meunier (2009), aponta a existência de 8 parques que representam apenas $0,2 \%$ da extensão do município, estes por sua vez são citados como de baixa densidade arbórea.

Em Campinas - SP, Santin e Cielo (2009) relatam que a vegetação existente nos parques e bosques municipais somam 38,01 ha o equivalente à 1,87\% da cobertura vegetal remanescente, com áreas que variam de 0,86 a 4,38 ha.

Em Sorocaba, a cobertura florestal nativa dos parques é muito variável, porém sua totalidade corresponde a 232,89 ha, o que equivale apenas a
$3,1 \%$ da cobertura vegetal nativa remanescente identificada por Mello (2012) em Sorocaba.

A etapa 2 permitiu excluir $14(42,5 \%)$ das áreas analisadas pelo critério tamanho (Tabela 1), pois apresentaram área menor que 5 ha e outras 14 $(42,5 \%)$ por não atingirem o percentual mínimo de vegetação nativa variável de acordo com seu tamanho (Tabela1).

As cinco áreas selecionadas na etapa 2, foram: $\mathrm{Pq}$. Natural Municipal Chico Mendes (figura 5), Pq. Municipal Bráulio Guedes da Silva (figura 4), Pq. Pedro Paes de Almeida (Horto Municipal José Lucindo Prado) (figura 3), Pq. Natural Municipal "Corredores da biodiversidade" (figura 2) e Pq. Municipal Mario Covas (figura 1), suas respectivas avaliações qualitativas estão descritas na Tabela 4. Apenas estes cinco parques selecionados são responsáveis por $47 \%$ da cobertura florestal total das áreas denominadas "parques", e são os espaços que melhor se enquadram no conceito de parque como unidade de conservação.

As cinco áreas selecionadas, foram analisadas por meio do índice construído com base na realidade ambiental atual de Sorocaba, na etapa 3. 
Figura 1: Imagem do Parque Mario Covas, sua delimitação territorial, ocupação por vegetação e entorno.

Figure 1: Image of the Park Mario Covas with their territorial delimitation, occupation by greenery and surrounding areas.

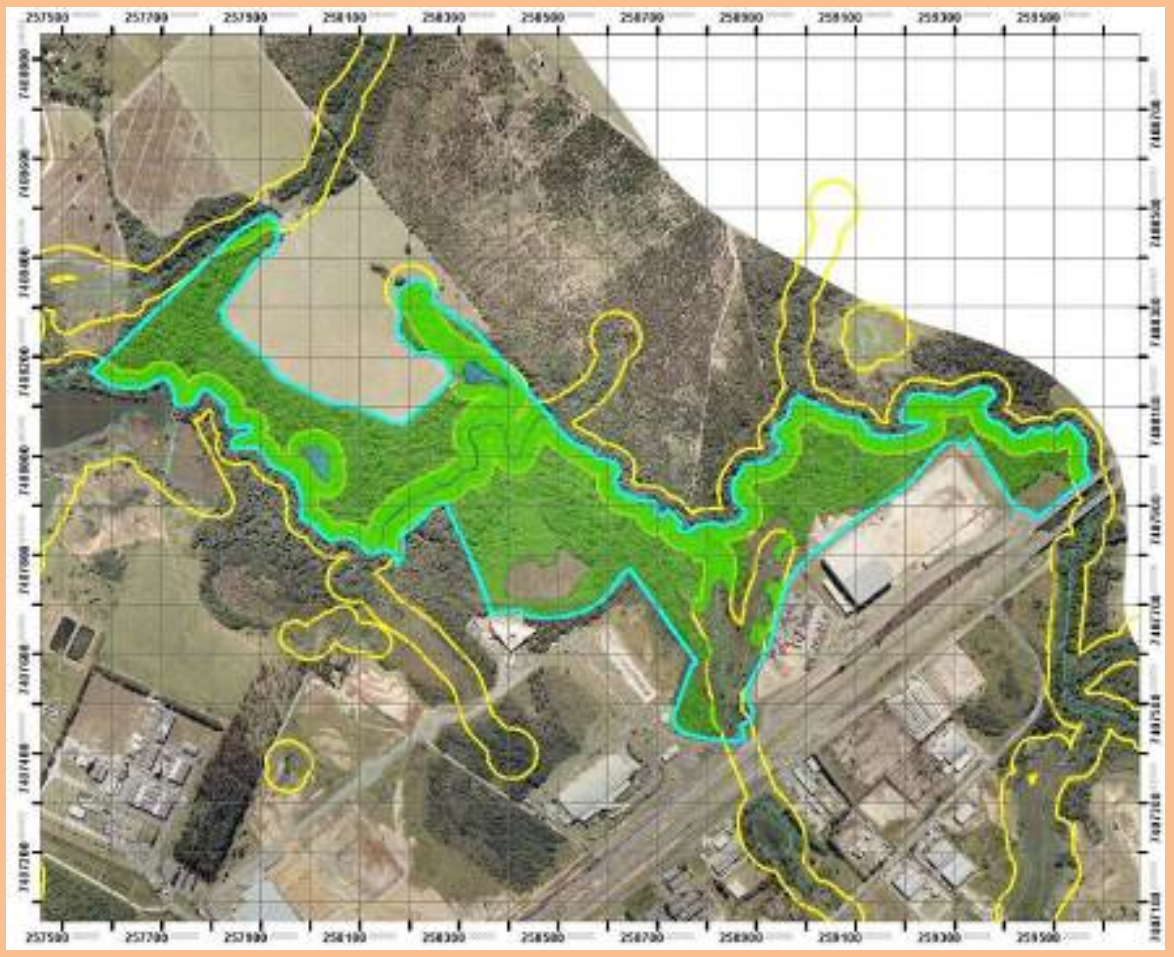

$$
\text { - }
$$

Pq. Municipal

Mario Covas

Área: $526.677 \mathrm{~m}^{2}$

Área Cobertura Vegetal: $437.856 \mathrm{~m}^{2}$

Área de Lago: $526.677 \mathrm{~m}^{2}$

\section{Legenda}

Darque_urbano

Mata_Cliar_Pq_Urbano

Vegetaçäo

Lago / Alagado

APP

0 \begin{tabular}{llll}
510 & $20 \quad 30$ & 40 \\
\hline
\end{tabular}

Figura 2: Imagem aérea do Parque. Corredores da Biodiversidade com sua delimitação territorial, ocupação por vegetação e entorno.

Figure 2: Aerial image of the Park of Biodiversity Corridors with their territorial delimitation, occupation by greenery and surrounding areas.

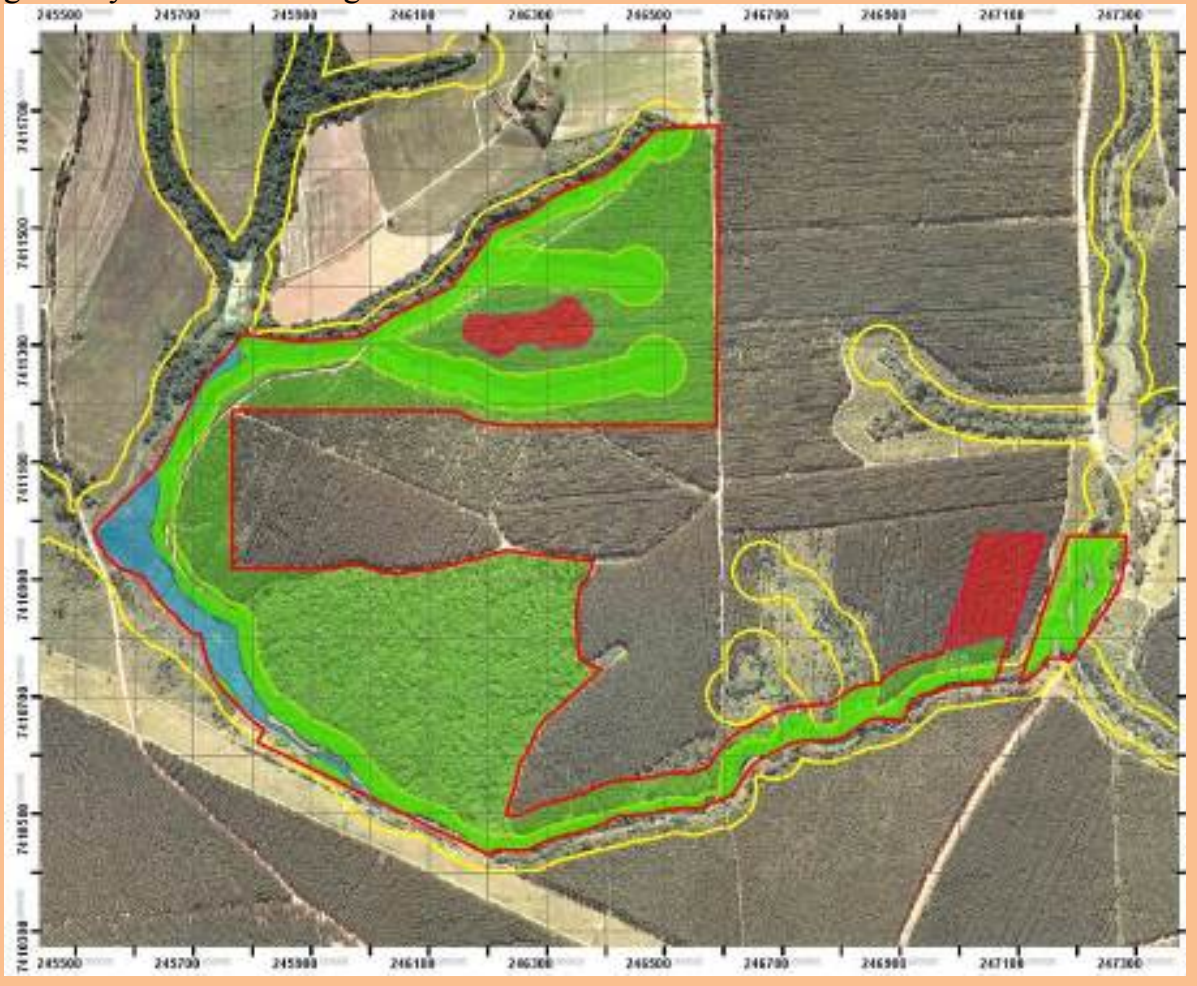$$
-1
$$

Pq. Municipal

Corredores da

Biodiversidade

Área: $624.768 \mathrm{~m}^{2}$ Área do Lago/ Alagado: $32.368 \mathrm{~m}^{2}$

Movimentação de terra: $3.299 \mathrm{~m}^{2}$

\section{Legenda}

$\square$ Parque_urbano

Mata_Cliar_Pq_Urbanos

Vegetaçäo

Lago / Alagado

APP

\begin{tabular}{llll}
$510 \quad 20 \quad 30$ & 40 & 0 \\
\hline
\end{tabular}

"PARQUES" EM PAISAGEM URBANA E SEU POTENCIAL PARA... 
Figura 3: Imagem aérea do Parque. Horto Municipal com sua delimitação territorial, ocupação por vegetação e entorno.

Figure 3: Aerial image of the Park. Municipal Horto with their territorial delimitation, occupation by greenery and surrounding areas.

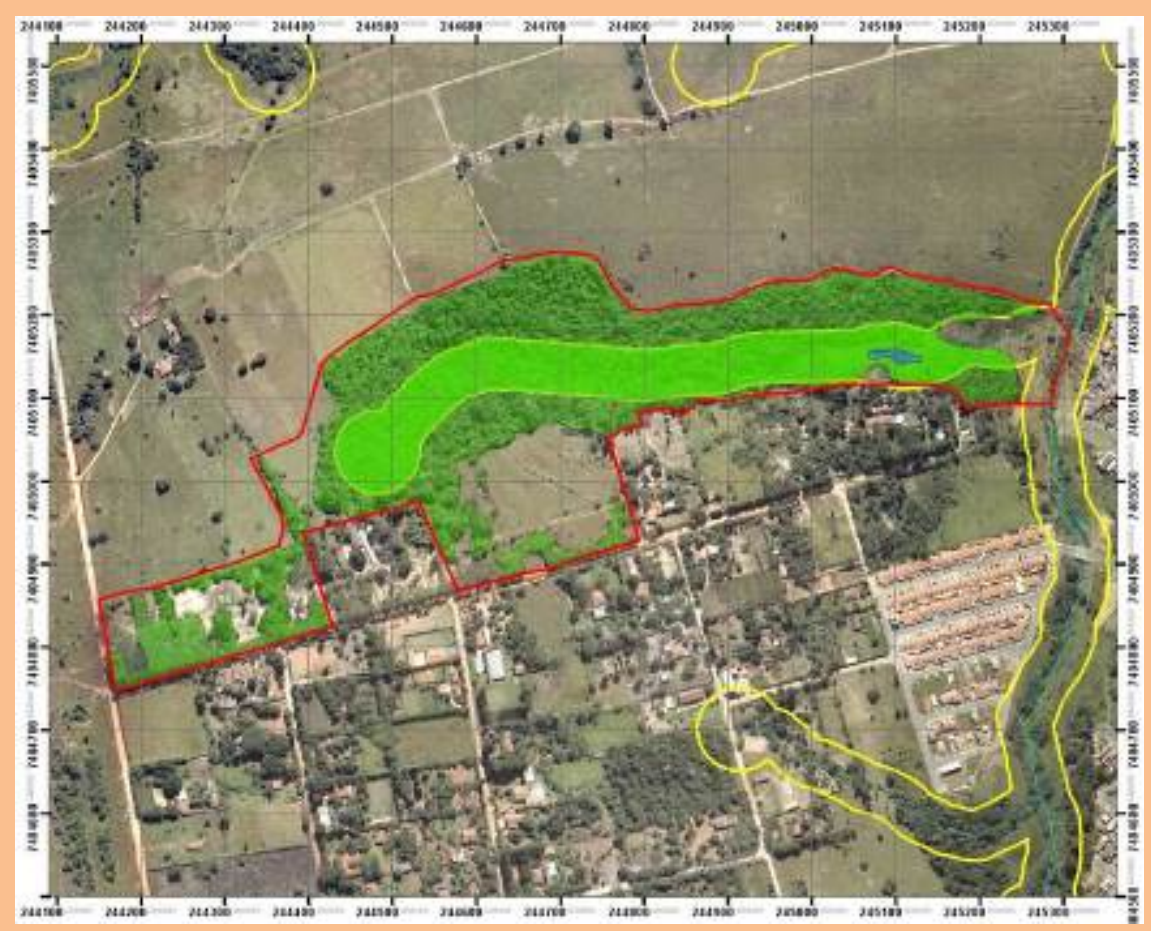

$$
-n_{=}^{n}
$$

Pq. Horto Municipal

Pedro Paes de Almeida

Área: $217.533 \mathrm{~m}^{2}$

Cobertura Vegetal: $156.716 \mathrm{~m}^{2}$

\section{Legenda}

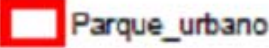

Mata_Cliar_Pq_Urbar

Vegetaçäo

Lago / Alagado

APP

$051020 \quad 30 \quad 40$

Figura 4: Imagem aérea do Parque. Bráulio Guedes com sua delimitação territorial, ocupação por vegetação e entorno.

Figure 4: aerial image of the Park. Bráulio Guedes with their territorial delimitation, occupation by greenery and surrounding areas.

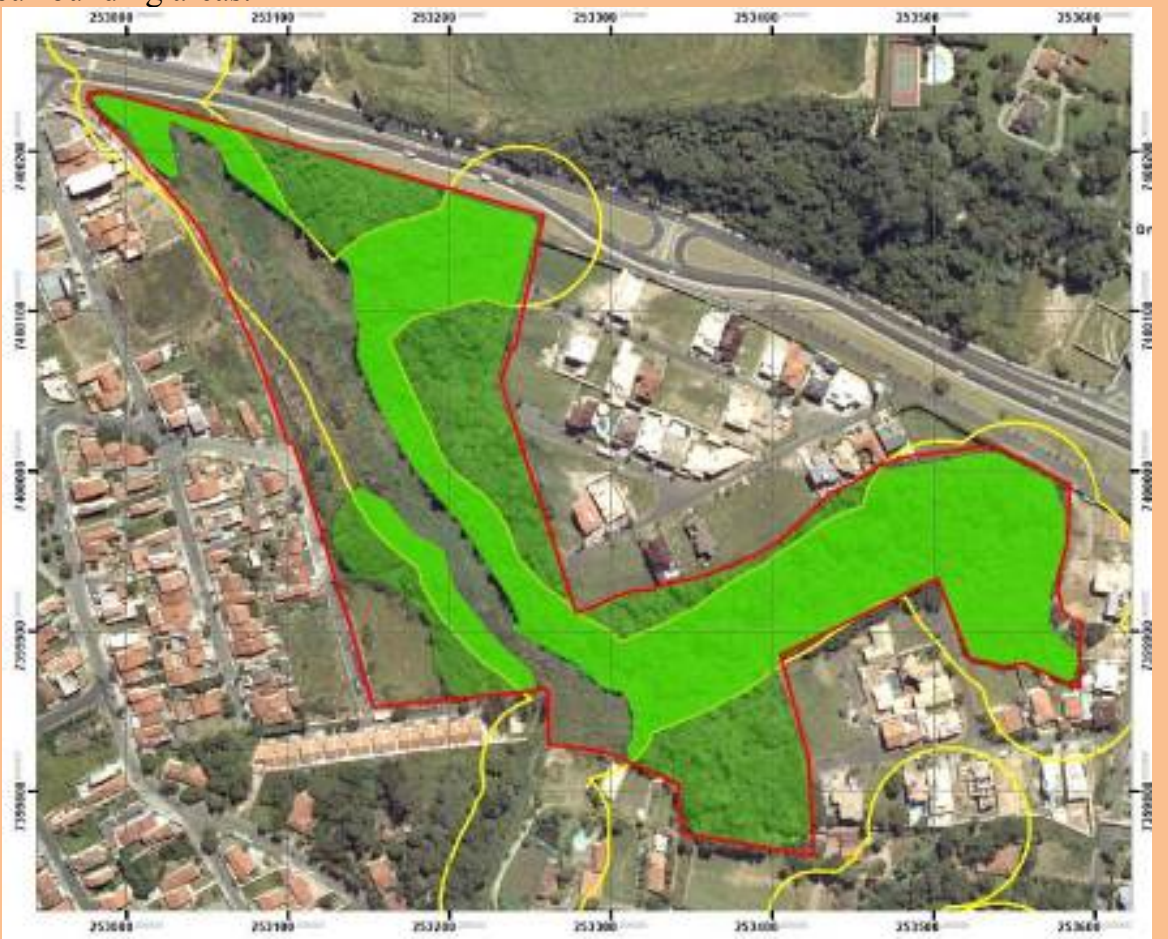<smiles>CC1(C)CCCC1(C)C</smiles>

Pq. Braúlio Guedes da Silva

Área: $93.760 \mathrm{~m}^{2}$

Área Cobertura Vegetal: $67.085 \mathrm{~m}^{2}$

\section{Legenda}

Parque_urbano

Mata_Criar_Pq_Urbano:

Vegetaçäo

Lago / Alagado

APP

$0 \begin{array}{llll}510 & 20 & 30 \quad 40 & 40\end{array}$ 
Figura 5: Imagem aérea do Parque Chico Mendes com sua delimitação territorial, ocupação por vegetação e entorno.

Figure 5: aerial image of the Park Chico Mendes with his territorial delimitation, occupation by greenery and surrounding areas.
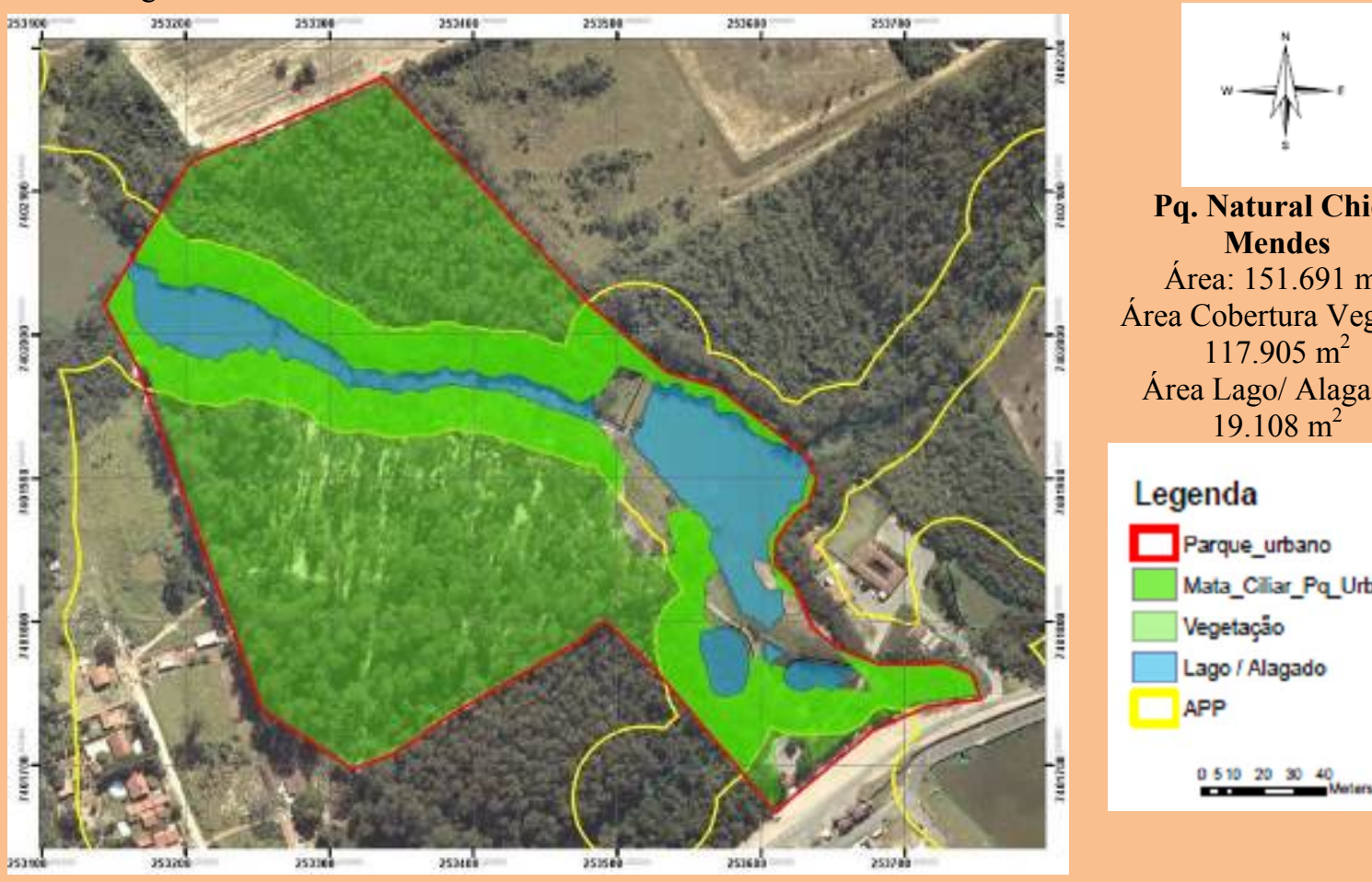

\section{Pq. Natural Chico \\ Mendes}

Área: $151.691 \mathrm{~m}^{2}$

Área Cobertura Vegetal:

$117.905 \mathrm{~m}^{2}$

Área Lago/ Alagado:

$19.108 \mathrm{~m}^{2}$

\section{Legenda}

$\square$ Parque_urbano

$\square$ Mata_Cliar_Pq_Urbanos

Vegetaçäo

$\square$ Lago / Alagado

APP

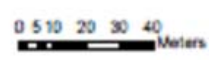

O resultado (Tabela 4) mostrou como melhor qualificado Pq. Mario Covas (Figura 1) com índice 89, de um máximo de 100, este valor mostra a relevância desta área em consideração à realidade atual de Sorocaba. Entretanto, este espaço passa pelo que Vallejo (2009) considera como ausência de territorialidade, dada ausência de políticas públicas transversais, uma vez que a área desde sua instituição não teve a elaboração e a efetivação de um plano de manejo, além de não apresentar estrutura mínima para recepção de público e desenvolvimento de pesquisas, apesar de estar situado numa região de grande importância ambiental, pois é um dos únicos mananciais do município onde há captação de água para abastecimento público, e sofrer grande pressão de indústrias localizadas no entorno, aguarda desde 2005 um plano de manejo e sua efetiva implantação.
O Pq. Natural Municipal "Corredores da Biodiversidade" (índice 73,5) é o único parque criado como unidade de conservação de acordo com o SNUC, tem grande área $(62,47$ ha), entretanto, com percentual de cobertura florestal nativa $(49,62 \%)$ na linha de corte, segundo o método proposto, em que pese a grande extensão a área de cobertura florestal nativa é relativamente pequena (31 ha), grande parte da área é coberta por silvicultura e áreas desprovidas de vegetação.

O Pq. Bráulio Guedes da Silva (índice 61,1) apresenta características naturais preservadas, sem uso público direto. Apesar de seu pequeno tamanho, apresenta outro pequeno fragmento a noroeste, e outro a nordeste, embora desconectado deste último devido a presença de uma grande avenida (Figura 1).

O Parque Chico Mendes (índice 57,8) tem características de uso intenso, com vegetação em 
estágio inicial em regeneração no sub-bosque de Eucaliptus sp na maior parte de sua área.

$\mathrm{O}$ último parque classificado, o Pq. Horto apresenta parte de sua área com uso intenso, onde funciona uma feira de troca, porém, tem uma grande área de vegetação nativa em estágio médio de regeneração e com grande potencial de conectividade com outras áreas sendo sua extensão territorial e percentual de vegetação considerável.

Tabela 4: Resultado das notas de avaliação qualitativa das áreas selecionadas como potenciais para categorização no SNUC no Município de Sorocaba, segundo o indicador construído neste trabalho.

Table 4: Result of qualitative assessment of selected areas as potential for categorization in the SNUC in the municipality of Sorocaba, second indicator built on this work.

\begin{tabular}{|c|c|c|c|c|c|}
\hline Indicador / Parque & CHM & HOR & BRG & BIO & MAC \\
\hline 1. Vegetação Nativa Arbórea em fragmento & 18,85 & 23,85 & 19,98 & 13,45 & 25,65 \\
\hline 2. Estágio sucessional da vegetação & 3,33 & 6,66 & 6,66 & 6,66 & 6,66 \\
\hline 3. Área territorial & 4 & 4 & 2 & 8 & 8 \\
\hline 4. Uso do solo no entorno & 1 & 1 & 1 & 8,2 & 10 \\
\hline 5. Proteção de manancial & 4 & 10 & 10 & 10 & 10 \\
\hline 6. Conectividade & 7,8 & 3,33 & 5,5 & 10 & 10 \\
\hline 7. Função & 3,33 & 3,33 & 10 & 10 & 10 \\
\hline & 46,9 & 57,8 & 61,1 & 73,5 & 89,0 \\
\hline
\end{tabular}

Nota: CHM - Pq. Chico Mendes; BRG - Pq. Bráulio Guedes; HOR - Pq. Horto; BIO - Pq. Corredores da Biodiversidade; MAC - Pq. Mario Covas.

Os dados evidenciam que não há normas, regras ou condicionantes para instituição do conceito de "Parque" em Sorocaba, Paecke et al (2011), identificaram o mesmo problema em Santiago Chile, esta ausência de padronização é citada pelos autores como ocorrente também no Canadá, Reino Unido, Alemanha e Estados Unidos. Costa (2011), destaca que esta situação foi identificada no Distrito Federal, e considerada inadequada a utilização do conceito "Parque" de forma generalizada.

Com relação ao tamanho foi observada a existência de áreas desde 0,28 ha até com 1.074 ha que utilizam a mesma terminologia. O percentual de cobertura florestal é outra variável discrepante, há casos de 0\% (Pq. "Maestro Nilson Lombardi”) até 96,42\% (Pq. "Steven Paul Jobs"), este por sua vez com a menor tamanho (0,28 ha).

A aplicação dos critérios propostos evidenciou que $85 \%$ dos espaços instituídos como parque no município de Sorocaba não podem se enquadrar na categoria de unidade de conservação de proteção integral "Parque Natural Municipal" (BRASIL, 2000), por não apresentarem características naturais relevantes para conservação.

Sendo assim, este estudo aponta para a necessidade de se utilizar termos distintos para áreas com características tão distintas, e como objetivos de manejo também diferenciados. Neste sentido o poder público municipal deveria repensar as áreas denominadas genericamente de "parques" e recategorizá-las em dois grandes grupos, o primeiro, constituído pelas 28 áreas eliminadas neste estudo, como Parques Urbanos, Praças e similares, e o segundo grupo, constituído pelas 5 áreas selecionadas neste estudo, como áreas protegidas. Ainda assim, talvez algumas destas 5 áreas não tenham todas as características necessárias para implantação de uma Unidade de Conservação de Proteção Integral, como é o caso dos Parques Naturais Municipais (BRASIL, 2000). No entanto estas áreas podem ser analisadas e repensadas como áreas protegidas, podendo 
constituir áreas de proteção integral (Parques Naturais Municipais) ou de uso sustentável (Florestas Municipais, Aries e outros). Na prática a instituição de normas e regras de gestão destes espaços, poderá restringir a generalização do termo "Parque" e possibilitará que a população reivindique políticas públicas mais eficazes em relação a implantação e gestão eficaz destes espaços.

Deve-se também evitar ainda a implantação de parques que não atendam diretamente ao interesse público, como é o caso do Pq. Pirajibu, seu decreto de criação delimitou uma das margens de um importante rio, o Pirajibu, entretanto, em campo observou-se que a margem desapropriada é a que menos apresenta vegetação nativa e atributos naturais relevantes para sua preservação, e que há implantação nesta margem de um emissário coletor de esgoto. Na maioria dos casos os parques tem sua origem territorial nas áreas verdes oriundas do parcelamento de solo. O plano diretor do município determina a instituição de $12 \%$ da área parcelada para instituição de áreas verdes, que não podem ser edificadas e devem servir ao lazer e recreação dos moradores, em alguns casos há implantação de equipamentos de lazer, pista de caminhada, ciclovia, playground, praças esportivas e são motivadores para instituí-los como parque.

Muitos ainda são áreas de preservação permanente (Lei Federal $n^{\circ} 12.651$, de 25 de maio de 2012), o que segundo a legislação já recebem severas restrições de uso, sendo em alguns casos, doados ao poder público como forma de evitar tributação territorial urbana, é o caso do Pq. Bráulio Guedes da Silva. É certo, também, que uma vez aceita a doação pelo poder público, emerge na seara jurídica, o dever do manejo efetivo das áreas.

Em alguns casos, há parques implantados em virtude de compensação ambiental, nesta situação observamos dois exemplos o Pq. Mario Covas e o Pq. Natural Municipal "Corredores da Biodiversidade" - PNMCB, este por força de compensação teve seu plano construído e custeado pela iniciativa privada.

\section{CONCLUSÃO}

Os resultados e as análises permitem concluir que o método utilizado mostrou-se adequado para as análises propostas, no entanto, vale salientar que o mesmo foi construído considerando o remanescente de áreas naturais em Sorocaba, e que sua aplicação em outras localidades dependerá de adaptações, ou seja, do contexto ambiental dos municípios analisados. $\mathrm{O}$ índice expressou coerência ao ordenar respectivamente os espaços com características físicas e biológicas mais próximas do conceito de unidade de conservação, conforme a lei do SNUC, mesmo aqueles com maior influência dos efeitos da urbanização.
O índice se mostrou eficaz e útil para apontar áreas prioritárias para conservação, a utilização do método se mostrou simples, de fácil aplicação, sem necessidade de estudos aprofundados que demandam tempo demasiado, recursos e pesquisadores especializados.

É concluso que em Sorocaba, não há distinção terminológica e conceitual na legislação municipal atual entre os espaços instituídos como "Parque" que apresentam caraterísticas relevantes para a instituição de unidades de conservação, daqueles espaços com características urbanísticas. 
Desta forma, faz-se premente a implantação de normas técnicas claras para criação e implantação dos espaços verdes livres protegidos com vocação para cumprir a função urbanística, daqueles cuja vocação seja unidade de conservação, assim como regular os distintos tipos possíveis que apresentem variáveis entre estes dois extremos conceituais.

É fundamental também que o ato jurídico de sua instituição seja acompanhado por regulamentos que garantam a gestão adequada destas áreas, através de previsão de dotação orçamentária mínima (variável em decorrência de sua extensão territorial), estudos técnicos que comprovem sua relevância frente a outros espaços ainda existentes, infraestrutura e garantia da elaboração e implantação de um plano de manejo no ato de sua instituição.

\section{REFERÊNCIAS BIBLIOGRÁFICAS}

ANGELIS, B.L.D.; CASTRO, R.M.; ANGELIS NETO, G. Metodologia para levantamento, cadastramento, diagnóstico e avaliação de praças no Brasil. Revista Engenharia Civil Um, número 20, pg. 57-70. 2004.

AVELAR, G. H. O.; SILVA NETO, J. C. Estudo de Impacto Ambiental de Áreas Verdes: uma proposta de planejamento e monitoramento. In: IV Congresso Nacional de excelência em gestão: Responsabilidade socioambiental das organizações brasileiras, p. 6 - 15, 2008. Anais. Niterói - RJ: 2008.

BARRAGÁN, K.B. Áreas Protegidas. Boletín GEAS, Vol. II, Número 2 (agosto), p. 9 -18. 2001. Disponível em: < http://issuu.com/vetsvidasilv/docs/bgeas200102> Acesso em: 10 de abril de 2013.

BASTÉN, V. G. Sobre sistemas, tipologias y estándares de áreas verdes em el planeamiento urbano. Revista Electrônica DU\&P Diseño Urbano y Paisaje V. II $\quad$ n. $06.2005 . \quad$ Disponível em: $<$ http://www.ucentral.cl/dap/pdf/000002.pdf $\geq$. Acesso em 28 de novembro de 2012.

BELLESTER-OLMOS, J.; CARRASCO, A.A. Normas para la classificación de los espacios verdes. Valência: Universidade Politécnica de Valência.Valência-Espanha. 187 p. 2001.

BENADUCE, M.I.V. Parque Itaimbé - Santa Maria/RS: Gênese de um espaço Público/ Privado. Dissertação de Mestrado - Programa Pós-graduação em Geografia e Geociências - Universidade Federal de Santa Maria. 138 p. 2007.

BENINI, S.M.; MARTIN, S.E. Decifrando as Áreas verdes públicas. Revista Formação, n.17, volume 2 - p. 63-80, 2010.

BORGES, L.F.R.; SCOLFORO, J.R.; OLIVEIRA, A.D. et al. Inventário de fragmentos florestais nativos e propostas para seu manejo e o da paisagem. Cerne, v. 10, n. 1, p. 22-38, 2004.

BRASIL, Secretaria do Orçamento e Coordenação da Presidência da República. Manual Técnico da Vegetação Brasileira. Rio de Janeiro: IBGE, 2012. Série Manuais Técnicos em Geociências. Disponível em: ftp://geoftp.ibge.gov.br/documentos/recursos_naturais/manuais tecnicos/manual tecnico_vegetacao brasileira.p df Acesso em: 12 de maio de 2013.

BRASIL. Lei Federal $n^{0} 9.985$ de 18 de julho de 2000 - Regulamenta o art. 225,§ $1^{\text {o }}$, incisos, I, II, III e VII da Constituição Federal, institui o Sistema Nacional de Unidades da Conservação e dá outras providências. Disponível em: < http://www2.planalto.gov.br/presidencia/legislacao > Acesso em: 22 de novembro de 2012. 
BRASIL. Lei Federal n ${ }^{\circ} 12.651$, de 25 de maio de 2012. Dispõe sobre a proteção da vegetação nativa; altera as Leis nos 6.938, de 31 de agosto de 1981, 9.393, de 19 de dezembro de 1996, e 11.428, de 22 de dezembro de 2006; revoga as Leis nos 4.771, de 15 de setembro de 1965, e 7.754, de 14 de abril de 1989, e a Medida Provisória no 2.166-67, de 24 de agosto de 2001; e dá outras providências. Disponível em: $<$ http://www.planalto.gov.br>. Acesso em: 31 de maio. 2013. [ [inks ]

BRUCCHERI, A. T.; NUCCI, J.C. Espaços Livres, Áreas Verdes e Cobertura Vegetal no Bairro Alto da XV, Curitiba-PR. Revista do Departamento de Geografia, 18 (2006), 48-59 p., 2006.

BURKE, F.; NAWAZ, H.; AZAM, M.; HAMZA,S.; HAQ, Q. Classification and Standardization of Parks North Nazimabad Towon-Karachi, Pakistan. Australian Journal of Basic and Applied Sciences, 3 (2): 853-856, 2009.

CAPORUSSO, Danúbia; MATIAS, Lindon Fonseca. Áreas verdes urbanas: avaliação e proposta conceitual. In: $1^{\circ}$ SIMPGEO/SP, Rio Claro, 2008. Disponível em: < $\underline{\text { www.rc.unesp.br/igce/simpgeo/71-87danubia.pdf. Acesso }}$ em 10/08/11> Acesso em: 01 de novembro de 2012.

CAVALHEIRO, F.; DEL PICCHIA, P.C.D. Áreas verdes: conceitos, objetivos e diretrizes para o planejamento. In: Anais do $1^{\circ}$ Congresso Brasileiro sobre Arborização Urbana e $4^{\circ}$ Encontro Nacional sobre Arborização Urbana. Vitória - ES, p.29-38, 1992.

CONSELHO NACIONAL DO MEIO AMBIENTE - CONAMA. Resolução n o 01, de 31 de janeiro de 1994. Regulamenta o art. $6^{\circ}$ do Decreto $n^{\circ} 750$, de 10 de fevereiro de 1993 para o Estado de são Paulo

CONSELHO NACIONAL DO MEIO AMBIENTE - CONAMA. Resolução no 10, de $1^{\circ}$ de outubro de 1993. Dispõe sobre parâmetros básicos para análise dos estágios de sucessão da Mata Atlântica.

COSTA, D. O. Parâmetros Normativos para a Gestão de Parques Urbanos do Distrito Federal. 2011, Dissertação de Mestrado - Programa Pós-graduação em Geografia da Universidade de Brasília. 130 p., 2011.

DURIGAN, G.; SIQUEIRA, M. F.; FRANCO, G.A.D.C.; RATTER,J.A. 2006. Seleção de fragmentos prioritários para a criação de unidades de conservação do cerrado no Estado de São Paulo. Revista Instituto Florestal, São Paulo. V. 18, n. único, p. 23-37, 2006.

FALCÓN, ANTONI. 2008. Espacios Verdes para uma ciudad Sostenible. IV Jornada Planificación y Gestión Sostenibe del Paisaje Urbana. Disponível em: $<$ http://www.dphuesca.es/pub/documentos/documentos ESPACIOS VERDES PARA UNA CIUDAD SOST ENIBLE_Sr_Antoni_Falcon_Consejero_Delegado_de_Materia_Verda_3217bfb5.pdf $>$. Acesso em 24 de maio de 2012 .

GALVÃO, W.; SANTOS, A.C.; PIACESKI, C.; GOOD, P. L.; NUCCI, J.C. Conservação da natureza no Município de Curitiba-PR. Revista GEOUERJ, número especial, Rio de Janeiro, 2003 (CD ROM).

GENTRY, A.H. The distribution and evolution of climbing plants. In: F.E. Putz \& H.A. Mooney (eds.). The Biology of Vines. Cambridge University Press, Cambridge, pp. 3-49, 1991.

GOMES, M.A.S. Parques urbanos de Ribeirão Preto-SP: Na produção do espaço, o espetáculo da natureza. Tese de Doutorado, Instituto de Geociências - UNICAMP, Campinas - SP, 279 p. 2009.

GUZZO, P. Estudo dos Espaços Livres de Uso Urbanos de Ribeirão Preto (SP): Acesso Público, Ínices e Base para Novos Instrumentos e Mecanismos de Gestão. Revista da Sociedade Brasileira de Arborização Urbana, v.1, n.1, 2006.

ISHIHATA, L. Bases para seleção de áreas prioritárias para implementação de unidades de conservação em regiões fragmentadas. São Paulo, 1999. 200 p. Dissertação (Mestrado) - PROCAM - Ciência Ambiental, Universidade de São Paulo - USP, 1999.

KLIASS, ROSA GRENA. Parques urbanos de São Paulo. São Paulo: PINI, 1993. 212p. 
KRONKA, F.J.N et al. Inventário Florestal da Vegetação Natural do Estado de São Paulo. São Paulo, SP: Secretaria do Meio Ambiente, Instituto Florestal, Imprensa Oficial, v. 1. 1-200 p. 2005.

LAVENDOWSKI, I.; MORAES, E.; MOSCATELLI, R. Gestão de Unidade de conservação em regiões metropolitanas: o caso do Parque Natural do Pedroso - Santo André, SP. In: I Seminário Nacional Paisagem e Participações: Práticas no espaço livre público, São Paulo- SP, 2007. Disponível em:

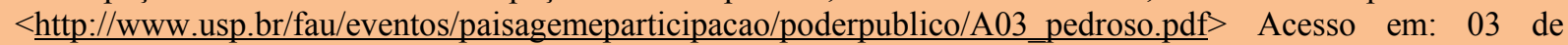
dezembro de 2012.

LIIRA, F.; LOHMUS,K.; TUISK, E. Old manor parks as potential habits for Forest flora in agricultural landscapes of Estônia. Biological Conservation, V. 146 (1) Elsevier - Feb. 1, p. 144 -154, 2012.

LEIRIA, 2012. Câmara Municipal de Leiria, Departamento de Planejamento e Ordenamento. Programação de equipamentos Coletivos paea a cidade de Leiria - Espaços Exteriores Urbanos. 26 p. Disponível em:

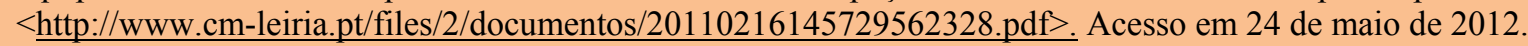

LIMA, A.M.L.P.; CAVAlHEIRO, F.; NUCCI, J.C.; SOUZA, M.A. del B.; FIALHO, N. de O. e DEL PICCHIA, P.C.D. Problemas de utilização na conceituação de termos como espaços livres, áreas verdes e correlates. In. II CONGRESSO BRASILEIRO DE ARBORIZAÇÃO URBANA, São Luís, Anais ... SBAU, p. 539-549,1994.

LOBODA, C.R.; DE ANGELIS, B.L.D. Áreas Verdes Públicas Urbanas: Conceitos, Usos e Funções. Revista Ambiência, Guarapuava, PR. V.1 n. 1 p. p. 125-139. Jan jun. 2005.

MACARTHUR, R.H.; WILSON, E.O. The theory of island biogeography. Princepton: Princepton University Press, 1967.

MELLO, K. Análise espacial de Remanescentes florestais como subsídio para o estabelecimento unidades de conservação. 2012. 82 pg. Dissertação de Mestrado do Programa de Pós-graduação em Diversidade Biológica e Conservação. Universidade Federal de São Carlos, Sorocaba, 2012.

MEUNIER, I.M.J. Percepções e expectativas de moradores do grande Recife-PE em relação aos Parques Urbanos. Nota Técnica. Revista da Sociedade Brasileira de Arborização Urbana, Piracicaba - SP, v.4, n-2, p.35-43, 2009.

MORSELLO, C. Áreas protegidas públicas e privadas: seleção e manejo. São Paulo: Ed. Annablume, $1^{\text {a }}$ ed. 2001.343 p., 2001.

OLIVEIRA, P. T. S. B. Sistema de Indicadores Ambientais: um modelo para o monitoramento de parques urbanos. São Paulo, 2007. Dissertação de Mestrado. Instituto de Pesquisas Tecnológicas do estado de São Paulo - IPT - Área de Gestão Ambiental. São Paulo - São Paulo. 134 p. 2007.

PAECKE, S. R; IBARRA, M.; MIRANDA, M.; PRECHT, A.; SALAMANCA, C., Concurso Políticas Públicas / 2011- Propuestas para Chile - Pontifica Universidad Católica de Chile. $<$ http://politicaspublicas.uc.cl/cpp/static/uploads/adjuntos_publicaciones/adjuntos_publicacion.pdf. $>$ Acess o em 29 de novembro de 2012.

PEREIRA, M. P. R. Espaços Verdes Urbanos - Contributo para a optimização do planejamento e gestão Freguesia de Oeiras e São Julião da Barra. Lisboa, 2011. Dissertação de Mestrado. Instituto Superior de Agronomia Universidade Técnica de Lisboa, Lisboa, 110p., 2011.

RANGEL, Helano Márcio Vieira; RIBEIRO, Homero Bezerra. A impossibilidade de desafetação de áreas verdes incorporadas ao domínio municipal por força de aprovações de loteamentos. In: Anais do XIX Encontro Nacional do CONPEDI. Fortaleza - CE 09 a 12 de Junho de 2010. Disponível em:

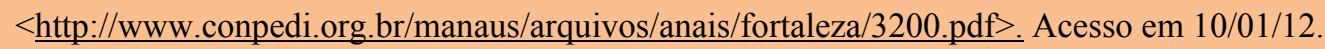


SANCHOTENE, M. do C.C. Conceitos e Composição do índice de áreas verdes. Boletim Informativo da Sociedade Brasileira de Arborização Urbana, n.1, p.4-9, 2004.

SANTIN, D; CIELO, R. F. Estudo Florístico e Fitossociológico de um fragmento florestal Urbano Bosque dos Alemães, Campinas - SP. Revista Brasileira de Botânica, V.25, n-3, p. 291-301, 2002.

SARAVIA, E.E.S.S. Los Parques como Recursos Naturales para la Educación Ambiental. Guatemala. Tesis Presentada a la junta directiva de la facultad de arquitectura. Universidad de San Carlos de Guatemala. Facultad de Arquitectura. 80 p. 2005.

SHIBUYA, Marina Mariko Kakizaki. Política urbana no plano diretor do município de Osasco. Revista da Pós-Graduação, UNIFIEO. Osasco, v.5, n.7, p.138-172, jun. 2011.

SICHE, R.; AGOSTINHO,F.; ORTEGA,E.; ROMEIRO,A. Índices Versus Indicadores: Precisões conceituais na discussão da sustentabilidade de países. Revista Ambiente \& Sociedade, Campinas - SP, v. X, n. 2. P. 137-148, 2007.

SOROCABA. Lei Municipal $\mathrm{n}^{\mathrm{o}}$ 10.060, de 03 de maio de 2012. Lei Ordinária. Ementa: Institui a Política Municipal de Meio Ambiente de Sorocaba, e dá outras providências. Disponível em: < http://www.camarasorocaba.sp.gov.br/sitecamara/proposituras/verpropositura $>$ Acesso em: 23 de novembro de 2012.

SOROCABA. Lei Municipal no 8.181, 05, de junho de 2007. Lei Ordinária. Ementa: Revisão da Lei 7.122 de 04/6/2004, que Instituiu o novo Plano Diretor de Desenvolvimento Físico Territorial do Município de Sorocaba, e dá outras providências. Disponível em: http://www.camarasorocaba.sp.gov.br/sitecamara/proposituras/verpropositura $>$ Acesso em: 23 de novembro de 2012.

SOUZA, P. C.A. Funções Sociais e Ambientais de Parque Urbano Instituído como Unidade de Conservação: percepção dos usuários do Parque Natural Municipal Barigui em Curitiba, Paraná. Dissertação de Mestrado. Programa de pós-graduação em gestão urbana do centro de Ciências Exatas e de tecnologia da Pontifícia Universidade Católica do Paraná. Curitiba- PR, 146 p., 2010.

VALLEJO, L.. Unidade de Conservação: Uma Discussão Teórica á Luz dos Conceitos de Território e Políticas Públicas. GEOgraphia, América do Norte, 4, set. 2009 . Disponível em:<http://www.uff.br/geographia/ojs/index.php/geographia/article/view/88/86>. Acesso em: 10 Jan. 2013.

WhATElY, M.; SANTORO, P. F.; GONÇALVES, B. C.; GONZATTO, A. M. (orgs.). Parques urbanos municipais de São Paulo. Subsídios para a gestão. São Paulo: Instituto Socioambiental, 124 p., 2008. 